\title{
Breakdown tests of glass fibre reinforced polymers (GFRP) as part of improved lightning protection of wind turbine blades
}

Madsen, Søren Find; Holbøll, Joachim; Henriksen, Mogens; Larsen, F M; Hansen, L B; Berthelsen, K

Published in:

Conference Record of the 2004 IEEE International Symposium on Electrical Insulation, 2004.

Link to article, DOI:

10.1109/ELINSL.2004.1380657

Publication date:

2004

Document Version

Publisher's PDF, also known as Version of record

Link back to DTU Orbit

Citation (APA):

Madsen, S. F., Holbøll, J., Henriksen, M., Larsen, F. M., Hansen, L. B., \& Berthelsen, K. (2004). Breakdown tests of glass fibre reinforced polymers (GFRP) as part of improved lightning protection of wind turbine blades. In Conference Record of the 2004 IEEE International Symposium on Electrical Insulation, 2004. IEEE. https://doi.org/10.1109/ELINSL.2004.1380657

\section{General rights}

Copyright and moral rights for the publications made accessible in the public portal are retained by the authors and/or other copyright owners and it is a condition of accessing publications that users recognise and abide by the legal requirements associated with these rights.

- Users may download and print one copy of any publication from the public portal for the purpose of private study or research.

- You may not further distribute the material or use it for any profit-making activity or commercial gain

- You may freely distribute the URL identifying the publication in the public portal 


\section{Breakdown tests of Glass Fibre Reinforced Polymers (GFRP) as part of Improved Lightning Protection of Wind Turbine Blades}

\author{
Søren Find Madsen, \\ J. Holboell \& M. Henriksen \\ $\emptyset$ rsted-DTU, Section of Electrical \\ Engineering \\ Elektrovej Building 325 \\ DK-2800 Lyngby. \\ Denmark
}

\author{
Flemming Møller Larsen \\ SSP Technologies A/S \\ Industrivej 12 \\ Nørre Broby \\ DK - 5672 Broby \\ Denmark
}

\author{
Lars Bo Hansen \\ LM Glasfiber A/S \\ Rolles Møllevej 1 \\ DK-6640 Lunderskov \\ Denmark
}

\author{
Kim Bertelsen \\ Vestas Wind Systems A/S \\ E. F. Jacobsensvej 7 \\ DK-6950 Ringkøbing \\ Denmark
}

\begin{abstract}
This paper addresses a need for analysing the interaction between electrical discharges and GFRP. A test method for evaluating the breakdown and withstand voltages for materials used in wind turbine blades has been developed. The method is based on IEC 243-3, Methods of test for electrical strength of solid insulating materials, and simulates the situation in a wind turbine blade, where a lightning discharge penetrates an insulating layer towards an inner earth conductor.
\end{abstract}

Different GFRP materials supplied by Danish wind turbine blade manufacturers have been tested. In the subsequent experiments, both the test methods and the results are evaluated. The different results are compared with respect to the GFRP materials' overall thicknesses, thickness of laminates and thickness of coatings.

Finally, some general conclusions and different statements on how to manufacture specimens with minimum likelihood of breakdown are stated.

\section{INTRODUCTION}

Lightning protection systems for wind turbine blades usually consist of a number of discrete lightning attachment points (receptors) and down conductor inside the blade, giving protection considered adequate for blades of length $20-30 \mathrm{~m}$ [1] (1).

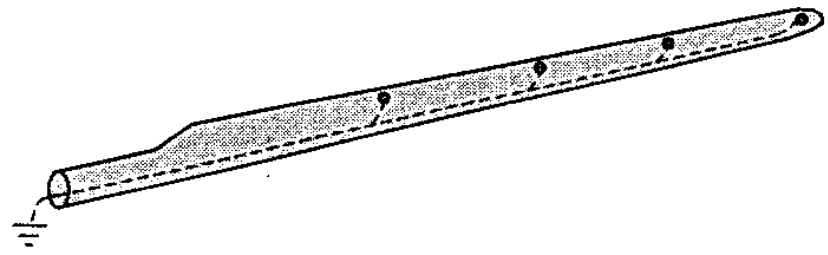

Figure 1 - Common lightning protection on modern wind turbine blades exceeding $30 \mathrm{~m}$.

For blades placed in humid or polluted environments, as on off-shore wind turbines, the risk of lightning not striking the receptors may be higher (due to the partly conductive surface layer) and the lightning might instead break through the blade material, creating an arc between the puncture and the down conductor. The high temperature from the arc results in a sudden pressure increase inside the blade, which is mostly followed by delamination of the blade [1]. In severe cases, the two other blades can be affected as well.

With the former paragraph in mind, the aim is to ensure lightning discharges continuing to the receptors (on the surface of the blade or in free air), and thereby reduce the number of skin penetrations.

Increasing the number of lightning receptors will possibly improve the lightning protection efficiency, but increase both the weight and the cost of the blade as well. By improving the materials' breakdown properties, the risk of lightning penetrating the surface decreases in relation to the probability of the lightning forming a flashover from the attachment point towards the receptor.

\section{TEST SETUP}

\section{Test specimen}

In order to simulate a situation where a lightning streamer is developing towards an earth conductor with an insulation surface in between, the following test specimen was proposed (2).

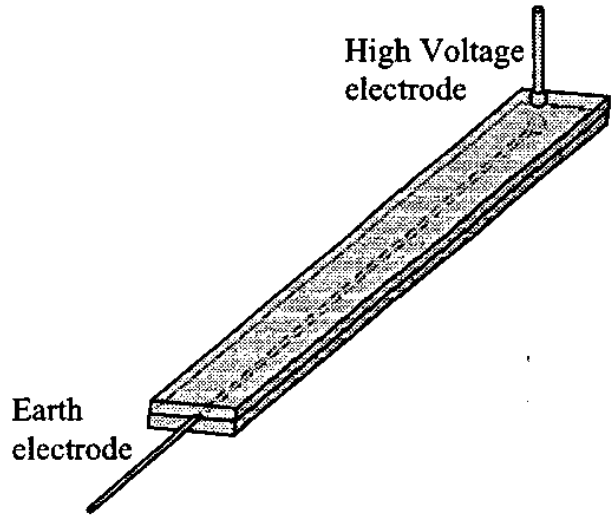

Figure 2 - Test specimen for breakdown and withstand voltage tests. 
The specimens are $1 \mathrm{~m}$ long and $15 \mathrm{~cm}-25 \mathrm{~cm}$ wide, and consist of a front side of glass fibre reinforced epoxy laminate (which is the part that is stressed), an earth electrode mounted in the middle of the specimen, and finally, the back side which is also made of glass fibre reinforced epoxy thick enough to avoid breakdown from this side. After the specimens have cured, a gelcoat is applied to the front side.

The earth electrode is a steel sphere with a diameter of 12.5 $\mathrm{mm}$, mounted on a brass rod with a diameter of $4 \mathrm{~mm}$. The brass rod is a bit longer than the specimen, as seen on (2), which enables termination of the ground wire.

As HV electrode, we use a similar steel sphere placed right above the earth sphere. The distance between the surface of the test specimen and the HV electrode is kept at $50 \mathrm{~mm}$ (3).

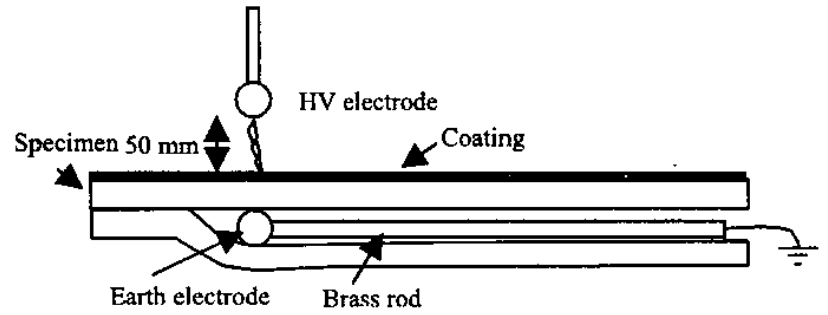

Figure 3 - Test specimen for breakdown and withstand voltage tests.

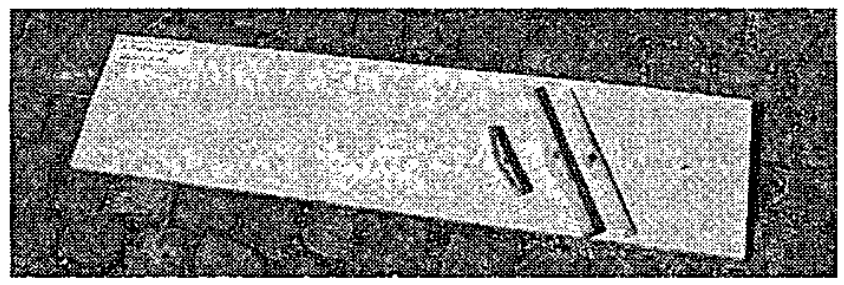

Figure 4 - Front side of specimen and cross sections.

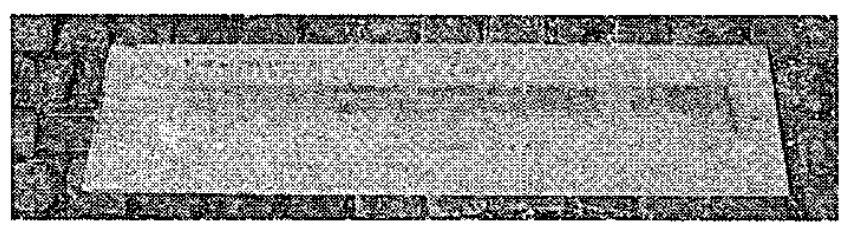

Figure 5 - Back side of specimen.

The design of the test specimen minimizes the material used for each specimen, while a large creeping distance, to avoid flashover, is still maintained. When a high voltage lightning pulse is applied on the HV electrode (3), an electrical discharge will form on the surface, searching for the weakest spot to develop a breakdown. Prior to testing, the surfaces of the specimens are cleaned with ethanol to ensure that no dirt or moisture will affect the flashover probabilities.

\section{Test method}

Wind turbine blades are usually hit within $2.5 \mathrm{~m}$ of the blade tip. In this region, the thickness of the surface skin is around 2-10 mm. Previous experiments carried out at The Technical University of Denmark have shown breakdown field strengths of GFRP materials in the order of $80-140 \mathrm{kV} / \mathrm{mm}$. With test specimen thicknesses of 1.2 to $5.6 \mathrm{~mm}$, a certain amount of flashovers at lower voltages was expected before a breakdown could occur. Earlier research has shown that breakdown voltages recorded during a situation where both breakdown and flashover occurs, are very much comparable to breakdown voltages measured without a flashover [3].

The lightning impulse was generated with a 12 stage Marx generator, with a maximum charging voltage on each stage of $100 \mathrm{kV}$. Due to the nature of the specimens, only four or six stages were necessary to create a breakdown. A standardized double exponential lightning impulse is defined with a rise time of 1.2 us $+/-30 \%$, and a fall time of 50 us $+/-20 \%$ [2]. A switching type pulse (usually 50-200/2000 us) would allow more time for streamers to develop [4], but here $1.2 / 50$ us pulses are used as the objective of this work is to study the breakdown properties of GFRP on relatively small specimens, and not the study of surface discharges.

A negative polarity on the high voltage electrode will result in formation of streamers at a lower voltage than with positive polarity. This streamer initiation is essential as the discharge is supposed to search the surface for defects finally leading to a breakdown. Recent work within the subject also indicates that negative polarity results in the lowest breakdown strengths [3]. A negative polarity was therefore chosen for these tests as well.

The mentioned experiences, combined with standardized methods, lead to the following procedure (6).

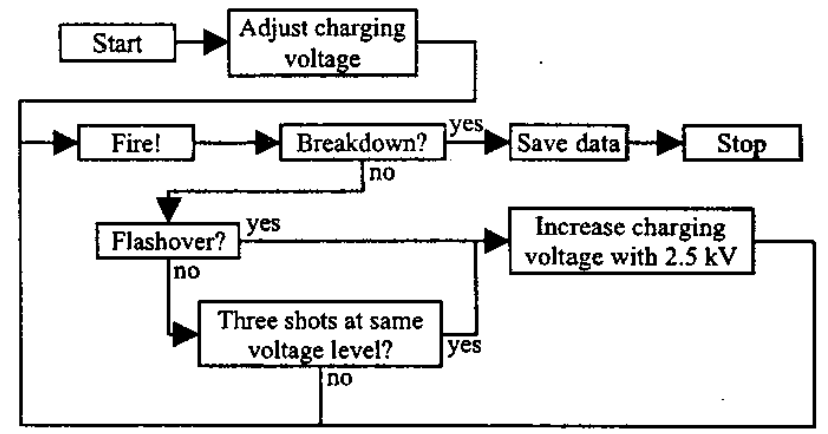

Figure 6 - Block diagram of test procedure.

A certain initial peak value of the impulse voltage is selected so that the specimen will survive at least three voltage levels. The generator is charged and three discharges at the selected voltage level are initiated. If neither breakdown nor flashover 
occurs within these three shots, the charging voltage is increased by $2.5 \mathrm{kV}(10-12 \mathrm{kV}$ increase in peak value), and three more discharges are initiated at this new voltage level. If a flashover occurs during one of three shots at the same level, the voltage is raised immediately to the next level. This way of increasing the voltage, depending on whether we have a flashover or not, is continued until we get the breakdown (6).

Charging voltage, peak value, rise and fall times are recorded for each discharge. For those discharges leading to flashover or breakdown, the time-voltage curve is saved as well.

\section{Evaluation of test setup}

The following section evaluates the test method. Throughout the text, capital letters in brackets refer to the specific test specimens listed in Table I and Table II.

In general, the experiments went very well. All specimens ended up having a breakdown through the front side, except one where the breakdown occurred in the interface between the front and the back side.

Experience and pictures of discharges have shown that the streamer approaching from the high voltage electrode tends to follow the brass rod towards the earth termination. In cases where flashover occurs, it is very obvious that the brass rod attracts the discharge. Photographs of discharges leading to breakdown have also shown that before the breakdown channel develops through the stressed specimen, streamers approach towards the earth termination (7).

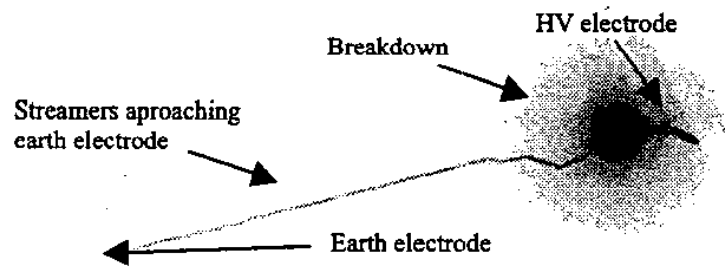

Figure 7 - Negative image of a breakdown beneath the high voltage electrode (right) and a streamer approaching the earth termination (left) (I).

Occasionally the breakdown occurs right between the steel spheres, but most often the breakdown is located some distance away from the high voltage electrode, between the earth sphere and the end of the brass rod. It is also very obvious from photos of the discharges, that the streamers search the surface above the brass rod, and when they find the weakest spot, they break through (8).

Some of the specimens experienced two separate breakdowns within the same discharge, a phenomenon commented in section "Results" (8).

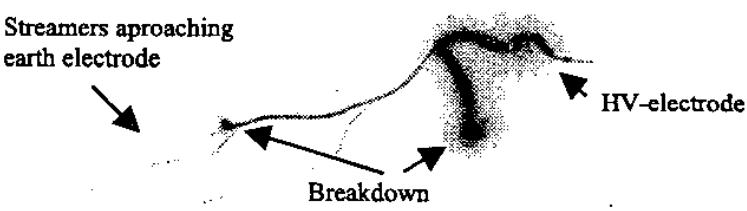

Figure 8 - Negative image of two breakdowns at the same specimen and streamers approaching the earth termination searching the surface for weakest spots (E).

\section{RESULTS}

The results are achieved in great cooperation with three different Danish wind turbine blade manufacturers. Conclusions are based on tests of a total of 55 specimens distributed on 17 different types. For each type of specimen, the dimension and the electrical properties are listed in table I and II.

Table I

Data for specimens, Dimension. Not all specimens are constructed similar, which explains the empty cells.

\begin{tabular}{|c|r|r|r|r|r|r|}
\hline Id. & $\begin{array}{c}\text { Coating } \\
{[\mathbf{m m}]}\end{array}$ & $\begin{array}{c}\text { Primer } \\
{[\mathbf{m m}]}\end{array}$ & $\begin{array}{c}\text { 1. layer } \\
\text { laminate } \\
{[\mathbf{m m}]}\end{array}$ & $\begin{array}{c}\text { Foam } \\
\text { [mm] }\end{array}$ & $\begin{array}{c}\text { 2. layer } \\
\text { laminate } \\
{[\mathbf{m m}]}\end{array}$ & $\begin{array}{c}\text { Overall } \\
\text { thickness } \\
\text { [mm] }\end{array}$ \\
\hline $\mathrm{A}$ & 0.16 & 0.50 & 2.10 & & & 2.76 \\
\hline $\mathrm{B}$ & 0.16 & 0.50 & 6.30 & & & 6.96 \\
\hline $\mathrm{C}$ & 0.60 & & 5.05 & & & 5.65 \\
\hline $\mathrm{D}$ & 0.60 & & 0.61 & & & 1.21 \\
\hline $\mathrm{E}$ & 0.60 & & 2.83 & & & 3.43 \\
\hline $\mathrm{F}$ & 0.40 & & 0.80 & 5.00 & 0.80 & 7.00 \\
\hline $\mathrm{G}$ & 0.40 & & 1.60 & & & 2.00 \\
\hline $\mathrm{H}$ & 0.60 & & 2.83 & & & 3.43 \\
\hline $\mathrm{I}$ & 0.60 & & 5.05 & & & 5.65 \\
\hline $\mathrm{J}$ & 0.60 & & 2.83 & & & 3.43 \\
\hline $\mathrm{K}$ & 0.48 & 0.50 & 2.10 & & & 3.08 \\
\hline $\mathrm{L}$ & 0.16 & 0.50 & 4.20 & & & 4.86 \\
\hline $\mathrm{M}$ & 0.60 & & 2.83 & & & 3.43 \\
\hline $\mathrm{N}$ & 1.20 & & 0.80 & 5.00 & 0.80 & 7.80 \\
\hline $\mathrm{O}$ & 1.20 & & 1.60 & & & 2.80 \\
\hline $\mathrm{P}$ & 0.32 & 0.50 & 2.10 & & & 2.92 \\
\hline $\mathrm{Q}$ & 0.16 & 0.50 & 2.10 & & & 2.76 \\
\hline
\end{tabular}

Three different analyses are performed.

1. A plot of the breakdown and highest withstand field strength versus the overall thickness of the laminate with coating applied (9).

2. Two plots of the breakdown and highest withstand field strength versus the thickness of the laminate for fixed coating thickness. Among the specimens are two separate series with two different but constant coating thicknesses, which is the reason for plotting two sets of data (11 and 12). 
3. A plot of the breakdown and highest withstand field strength versus the thickness of the coating for fixed laminate thickness (13).

Table II

Data for specimens, Electrical properties

\begin{tabular}{|c|r|r|r|}
\hline Id. & $\begin{array}{c}\text { Breakdown } \\
\text { voltage [kV] }\end{array}$ & $\begin{array}{c}\text { Withstand } \\
\text { voltage [kV] }\end{array}$ & $\begin{array}{c}\text { Time to } \\
\text { breakdown [us] }\end{array}$ \\
\hline A & -130.7 & -132.5 & 5.3 \\
\hline B & -133.5 & -149.7 & 0.8 \\
\hline C & -135.5 & -184.9 & 1.3 \\
\hline D & -115.9 & -119.3 & 4.1 \\
\hline E & -99.8 & -107.3 & 2.3 \\
\hline F & -104.6 & -136.9 & 2.3 \\
\hline G & -95.6 & -95.5 & 3.1 \\
\hline H & -104.3 & -102.6 & 2.6 \\
\hline I & -144.6 & -169.6 & 2.9 \\
\hline J & -124.4 & -127.2 & 2.7 \\
\hline K & -141.8 & -130.2 & 2.2 \\
\hline L & -142.7 & -134.1 & 1.1 \\
\hline M & -128.6 & -121.2 & 3.9 \\
\hline N & -147.0 & -152.2 & 4.9 \\
\hline O & -106.83 & -105.70 & 4.87 \\
\hline P & -113.1 & -147.2 & 0.9 \\
\hline Q & -128.2 & -138.5 & 1.5 \\
\hline
\end{tabular}

All the different data points for each test specimen are plotted with blue ' $t$ ' signs for the breakdown field strength and red ' $o$ ' for the highest withstand field strength. Furthermore, a straight line representing the best linear fit to the data, based on the mean values of field strengths for each thickness, is drawn. The lines are marked with '...' for the highest withstand field strength and '__' for the breakdown field strength. The intention is not to compare different actual values, but to recognize a certain tendency.

If the purpose is to compare field strengths measured in the laboratory with actual field strengths in wind turbine blades, it is necessary to mention the electrode configuration. This paper only aims at defining some general aspects concerning the use of composite materials in a high voltage environment. The term 'average electric field' only serves to compare values within this paper. In other words, different electrode configurations will give higher or lower breakdown field strengths.

\section{$E_{B}$ versus overall thickness}

Thirty eight of the specimens were constructed in a similar manner with a layer of laminate covered by a layer of coating. For these specimens it is possible to plot the breakdown and highest withstand voltage to compare results at different total thicknesses. This analysis does not distinguish between different relations of coating thickness and laminate thickness, which is done in section " $E_{b}$ versus laminate thickness" and " $E_{b}$ versus coating thickness".

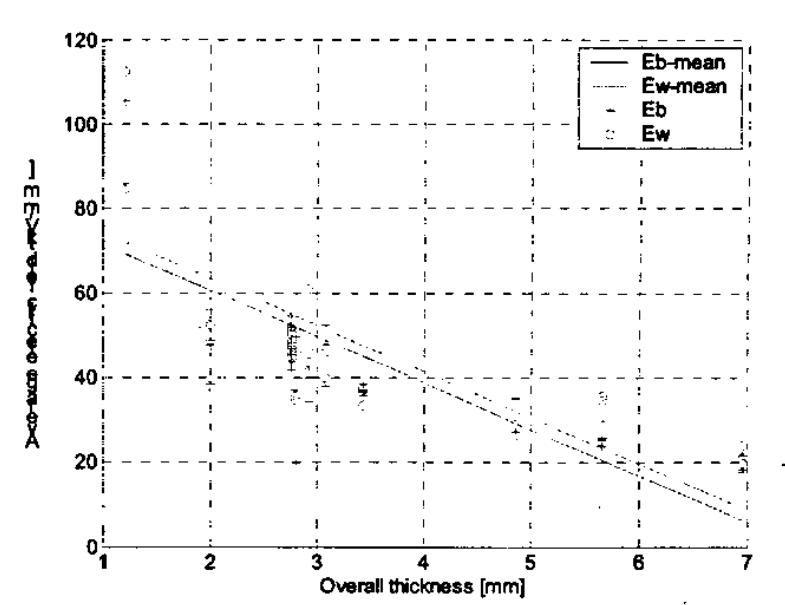

Figure 9 - Average electric field at breakdown voltage and highest withstand voltage versus overall thickness.

Due to the comprehensive manufacturing processes, it is very difficult to maintain a high degree of homogeneity in large composite structures. Although an actual blade surface seems very smooth, and all precautions have been taken to avoid differences in material thicknesses, the situation is somewhat different. By plotting field strengths versus overall thicknesses for different kinds of material compositions, the natural inhomogeneities are to some extent taken into account (9).

The results show a clear tendency of decreasing breakdown field strength with increasing overall thickness. Although the data are encumbered with a large dispersion, an indication of the volume effect is present.

\section{Investigations of material defects}

It was suspected that breakdown is influenced by material defects, and in order to classify these defects, cross sections of the specimens were investigated with a microscope (10).

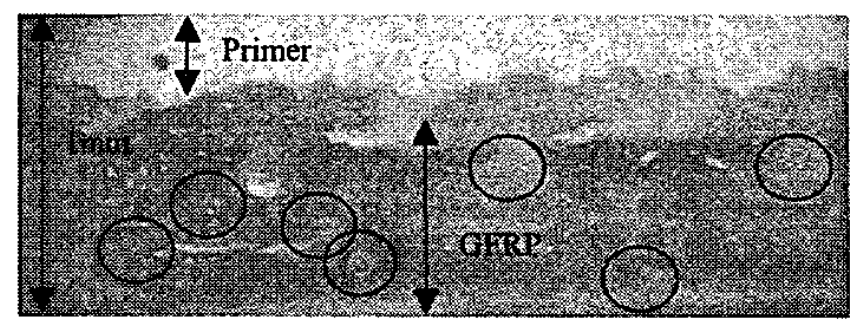

Figure 10 - Air filled cavities of varying sizes located randomly in all the different types of laminate.

Close up pictures of cross sections revealed a rather large amount of air filled cavities present in all the different types of laminate. The interface between coating, primer and laminate also showed a risk of containing impurities and other defects. 
Subsequent to these microscopic investigations, volume and mass of randomly selected specimens were measured. This in connection with burnout tests for measuring specific glass and resin content, enabled an estimate of the air content relative to the total volume of the specimen.

The specific volume of air in twelve different specimens were estimated, with a span from $0 \%$ to $13 \%$ and an average value of $5.8 \%$. When the volume of a stressed material with a certain content of air increases, the probability of finding a cavity large enough to initiate a breakdown at the applied voltage increases as well. Minor discharges in these small cavities will indeed affect the breakdown voltage.

\section{$E_{B}$ versus laminate thickness}

An estimation of the laminate's influence on the electrical properties is made in this section. Two separate series of test specimens (A, Q, L, B) and (J, C, M, D, I, E, H) were constructed with the same coating layer, but with different laminate thicknesses.

Again, figures of breakdown voltage and the highest withstand voltage, with respect to the laminate thickness, are plotted (11) and (12).

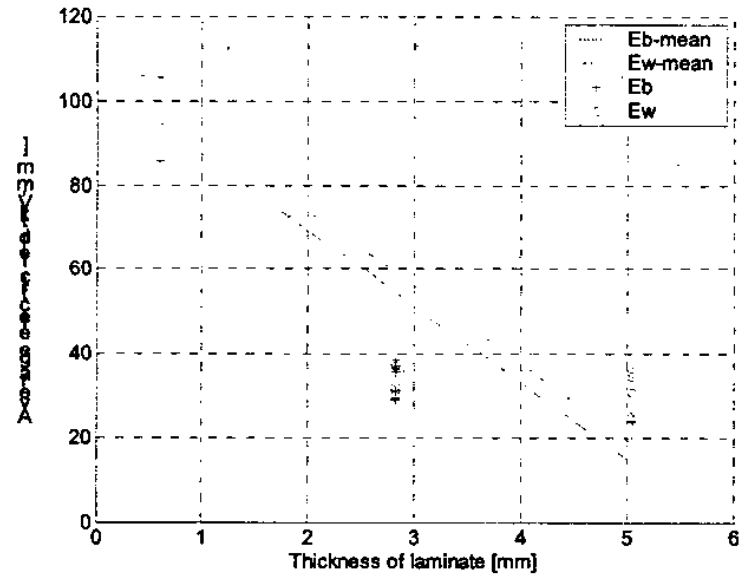

Figure 11 - Average electric field at breakdown voltage and highest withstand voltage versus thickness of laminate for fixed coating thickness of $0.6 \mathrm{~mm}(\mathrm{~J}, \mathrm{C}, \mathrm{M}, \mathrm{D}, \mathrm{I}, \mathrm{E}, \mathrm{H})$.

The breakdown field strength still tends to decrease with increasing laminate thickness (11). Despite the lack of measurements at thicknesses between $1 \mathrm{~mm}$ and $2.5 \mathrm{~mm}$, it seems that a well fitted curve would be steeper in the beginning of thin specimens than at the end. This again indicates the presence of a volume effect.

The volume effect states, that when the specimens are thin, the probability of finding a cavity of critical size located between the electrodes is smaller, than with thicker specimens. At a certain electric field, the electrons accelerated in an air filled cavity will gain energy proportional to the free mean distance between subsequent ionizing collisions. The maximum energy gained by electrons does to some extent depend on the physical size of cavities. In other words, by critical size means a size sufficiently large so that electrons gain enough energy to cause a breakdown at the applied field.

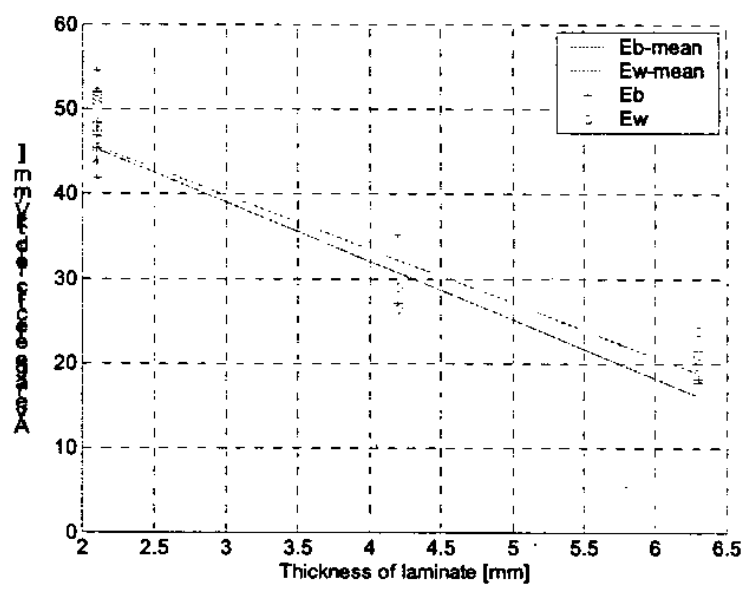

Figure 12 - Average electric field at breakdown voltage and highest withstand voltage versus thickness of laminate for fixed coating thickness of $0.16 \mathrm{~mm}$, and fixed primer thickness of $0.50 \mathrm{~mm}(\mathrm{~A}, \mathrm{Q}$, L, B).

Results from the second series with fixed thickness of coating and primer shows almost similar results (12). The field strength decreases with increasing laminate thickness, but not as rapidly as before.

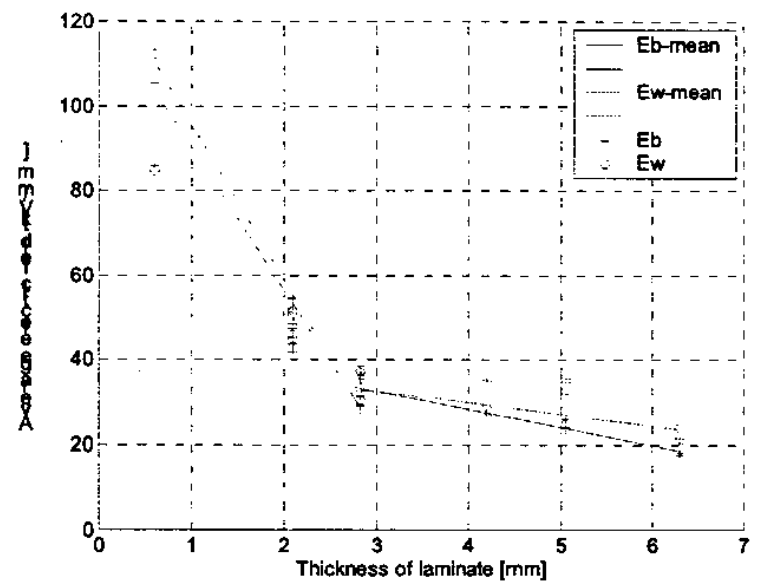

Figure 13 - Average electric field at breakdown voltage and highest withstand voltage versus thickness of laminate for fixed coating and primer thickness of either $0.6 \mathrm{~mm}$ coating or $0.16 \mathrm{~mm}$ coating and $0.5 \mathrm{~mm}$ primer (J, C, M, D, I, E, H) and specimens (A, Q, L, B).

The thinnest laminate in this second series is $2.1 \mathrm{~mm}$, with breakdown strengths between $47 \mathrm{kV} / \mathrm{mm}$ and $52 \mathrm{kV} / \mathrm{mm}$. If these data were placed in the former diagram, they would almost fit a straight line with a smaller gradient (11). Although 
the two types of specimens (coating and laminate) are of different origin and slightly different thickness, a plot with all data from specimens $(A, Q, L, B)$ and $(J, C, M, D, I, E, H)$ is made (13).

The tendency lines are drawn in two steps. The first two lines with the highest gradients are based on the data sets at the three thinnest specimens, up to $2.8 \mathrm{~mm}$. The second two lines are based on the four thickest specimens with laminate thicknesses from $2.8 \mathrm{~mm}$ to $6.3 \mathrm{~mm}$.

This picture indicates that two different mechanisms could be present. Initially the same explanation as mentioned earlier is valid, where the possibility of having a cavity of critical dimension relative to the applied field is smaller for thinner specimens than for thicker (13).

When the specimens' thicknesses get above a certain value, the volume is so filled with cavities of different sizes, that a further increase in volume does not increase the probability of finding larger cavities. These larger cavities (if they were present) might decrease the breakdown strength even further.

Exactly at which thickness this phenomenon takes place must depend on further experiments.

\section{$E_{B}$ versus coating thickness}

Another parameter to vary is the thickness of the coating. A series of specimens made with the same laminate thickness of $2.1 \mathrm{~mm}$, a primer thickness of $0.5 \mathrm{~mm}$, and coating thicknesses varying between $0.16,0.32$ and $0.48 \mathrm{~mm}$, enables this comparison.

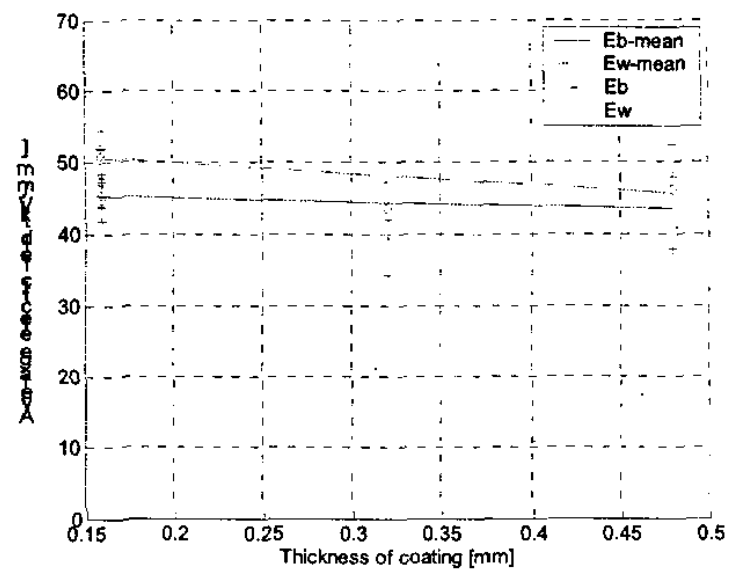

Figure 14 - Average electric field at breakdown voltage and highest withstand voltage versus thickness of coating for fixed laminate thickness of $2.1 \mathrm{~mm}$, and fixed primer thickness of $0.50 \mathrm{~mm}(\mathrm{~A}, \mathrm{Q}, \mathrm{P}$, K).

Interestingly a change in coating thickness does not affect the breakdown or withstand voltages much. The very small gradient of the mean value curves indicate a volume effect in the coating. Small defects and cavities are visible in the coating when looking at specimens in a microscope, but they are not as dominating in size and number compared to the laminate. The minor decrease in breakdown and withstand fields might be a coincidence.

\section{Initial breakdowns}

On all figures it is seen that the withstand field strength seems a bit higher than the breakdown field. This fact indicates that a breakdown is formed within several impulses. Some initially very high stresses may start minor discharges in the air filled cavities, discharges that suddenly lead to formation of the final breakdown. This hypothesis is supported by some photos taken of initiating breakdowns and final breakdowns of specimens (L) and (B) (15) (16).
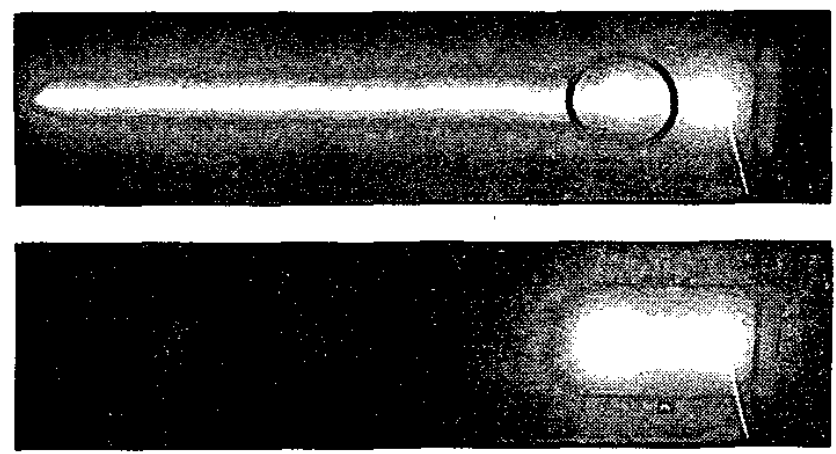

Figure 15 - Image of breakdown in specimen (L). Note the strong light on the first picture indicating an initial breakdown.

The first photo was taken of the discharge just before the discharge leading to breakdown (the second photo). Only the final breakdown captured on the second photo was visible at the time-voltage curve (15). The exact same situation happened with specimen (M). An image of the discharge just before the one leading to final breakdown showed an initial breakdown which was not visible on the time-voltage curve (16).
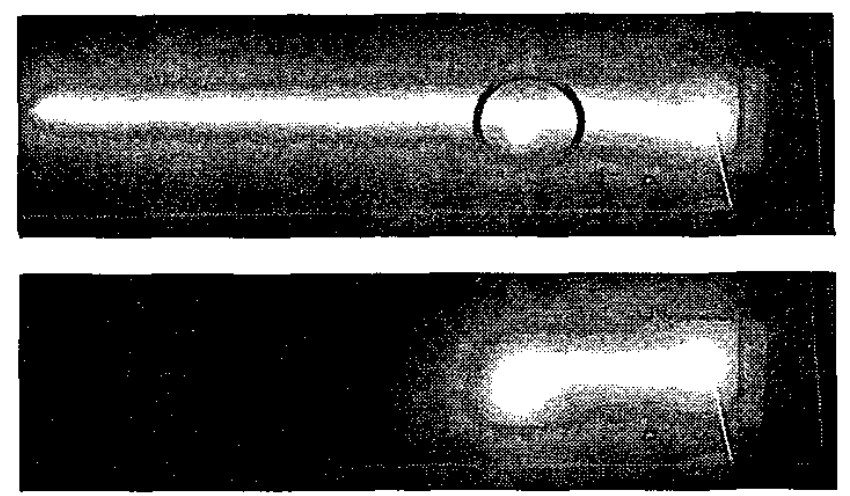

Figure 16 - Image of breakdown in specimen (M). Note the strong light on the first picture indicating an initial breakdown 
Relating these observations with lightning attachments to wind turbine blades emphasizes something very important. Most often, lightning attaches to the discrete lightning receptors connected to the inner down conductor. But situations occur where streamers develop along surfaces where charges, streamers or melted objects of different potential or even the opposite polarity are present on the opposite side of the laminate. That may result in partial breakdown and weakening locally, and therefore the lifetime of the blade regarding lightning may be decreased after some of these flashovers.

\section{Copper mesh or carbon fibres}

For four of the test specimens the earth electrode (brass rod with steel sphere) was replaced with a copper mesh or a carbon fibre laminate. The breakdown of these specimens occurred on the edge of the mesh/laminate, which is rather obviously due to the field enhancement at sharp edges. If blade manufactures intend to protect their blades with flat structures like copper mesh or carbon fibre laminate, the lightning will most certainly attach to the edges of these structures.

Dimensioning of this type of protection usually consists of a calculation of the maximum temperature rise in the mesh or lamina due to resistive power loss in vicinity of the arc root attachment point. When lightning attaches to the edge of a mesh or laminate, initially only half the amount of material is available for current and heat conduction until the current has spread across the carbon or copper cross section. This might lead to unforeseen damage.

Particularly for the two specimens with copper mesh electrode, two separate breakdowns on each specimen were seen (17).

An explanation of this phenomenon (although two specimens are not really enough for a general conclusion) could be the impedance of the thin copper mesh. If this impedance is too large, critical voltages along the copper will build up. Due to these impedances the potential will not decay immediately after the first breakdown. This allows time enough for further streamer initiation towards the earth electrode. A voltage drop along the copper mesh combined with the development of streamers towards the earth termination applies a large stress on new areas of the specimens (17).

Nearly all the energy is released in the first breakdown, which does not leave much for the second one. This is also very evident when looking at the image where the second breakdown is of a much smaller extent than the first one (17). The time-voltage curve of the breakdown in specimen (E) clearly indicates that a time of 0.7 us has elapsed from the first to the second breakdown (18).

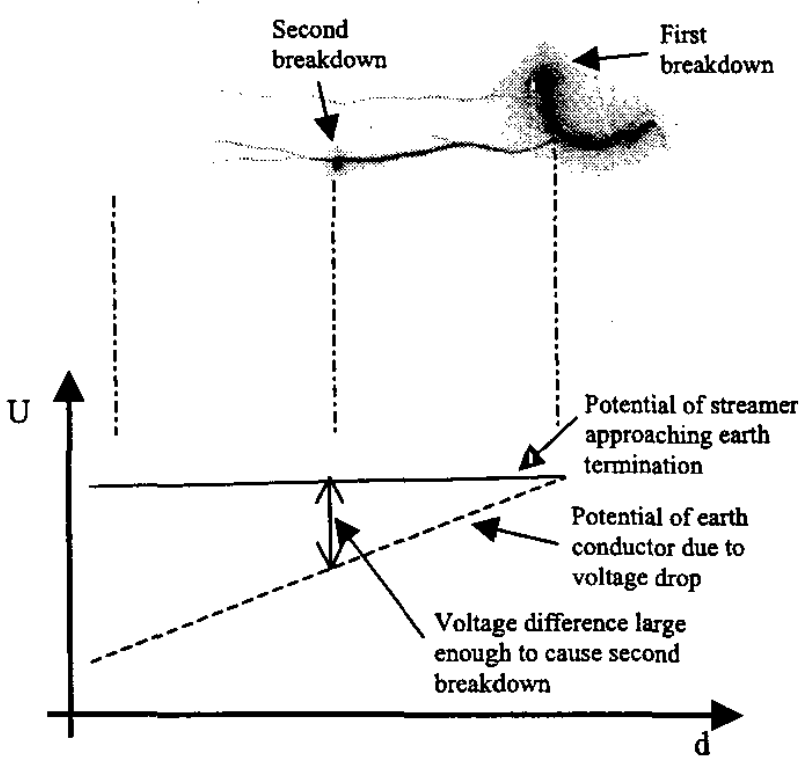

Figure 17 - Negative image of two breakdowns at specimen 'E'. The potential after the first breakdown (right) decays so slowly that further streamer development is possible. The impedance of the copper mesh together with the streamers at high potential implies a large stress on new areas of the material. This results in a second breakdown (left).

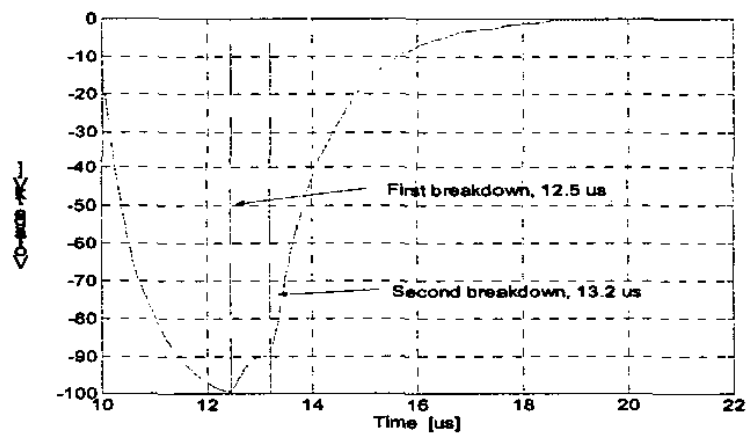

Figure 18 - Time-voltage curve for breakdown in specimen ' $E$ '.

When lightning has attached to a blade, the current must be conducted safely towards the blade root flange. The conductor in this case must have an impedance low enough to ensure that no critical voltage drop along the conductor occurs. This could result in further streamer propagation on the blade surface, and finally a breakdown towards a streamer initiated from the inner down conductor.

\section{SUGGESTIONS FOR MANUFACTURING IMPROVEMENTS.}

Although air content is a very difficult parameter to adjust, manufacturers must try to minimize the amount of air filled 
cavities in the laminates. As wind turbine blades are continuously subjected to a higher risk of lightning attachment, the structure must be seen not only as a mechanical structure, but also as a high voltage component.

Initial breakdowns during flashovers are regarded rather problematic in relation to actual lightning attachment to wind turbine blades. The aim must be to avoid discharges developing on the surface that are not connected to the receptors, and to avoid discharges inside the blade perhaps by encapsulating the down conductor system.

Manufacturers that tend to develop lightning protection consisting of flat electrodes or flat down conductors must be aware of the field enhancement at possible sharp edges. This field enhancement might initiate streamers at lower voltages than expected for conductors with a circular cross section.

The impedance of down conductors must be kept as low as possible. If this is not the case, critical voltage drops will develop during a lightning strike, possibly leading to streamer propagation from the inner down conductor. When these streamers approach the inner surface of the blade they are possibly attracted to streamers along the outside surface. The pair of streamers at different potentials on each side of the blade skin apply electrical stress on a larger area. This stress may, in worst cases, lead to subsequent breakdowns.

\section{CONCLUSION}

The above experiments indicate that the breakdown and withstand field strengths decrease by increasing the thickness of composite materials used for blade manufacturing. This is both valid when dealing with the compound specimen consisting of laminate and coating, and when treating the laminate alone. Furthermore it suggests that up to a certain thickness, the field strength decreases more rapidly than beyond this point. The phenomenon is explained by a volume effect partially caused by a relatively large content of air filled cavities.

When eliminating the laminate thickness, and comparing different thicknesses of coating, the breakdown and withstand field strengths are not much affected. There have been observed small cavities and impurities in the coating layer, but to a much lower extent than in the laminate.

Photos of discharges have revealed the possibility of initial breakdowns occurring during a flashover. The initial breakdowns are not visible on the time-voltage curve, but several series of pictures prove their existence.

Four specimens had the earth sphere and the brass rod replaced by either a copper mesh or a carbon fibre laminate.
Breakdowns to these specimens always happened to the edges of the electrodes.

Earth conductors/electrodes with rather large impedances imply a voltage drop development along the earth conductor. In two cases, this led to the formation of two breakdowns in one single discharge.

\section{FURTHER WORK}

Within this work, three ideas for future work have arisen.

1. Results obtained with negative polarity must be compared with similar results with positive polarity. International standards suggest tests with negative polarity, but the effects of polarity reversal must also be investigated [2].

2. The cost of manufacturing test specimens must be taken into account. During this work, some ideas have been proposed for smaller specimens $(15 \mathrm{~cm} \times 15 \mathrm{~cm})$ where the bottom side of the specimen is resting on a plane electrode with round edges immersed in silicon oil. The top side is in free air and the voltage is applied from a steel sphere $50 \mathrm{~mm}$ above the surface of the specimen. Initial tests show very promising results.

3. In the very near future, tests of large wing tips will be performed in the high voltage laboratory at The Technical University of Denmark. This will allow comparison between 'full scale' tests and tests on smaller and much cheaper specimens.

\section{REFERENCES}

1. IEC TR $61400-24,2002$, Wind turbine generator systems - Part 24: Lightning protection.

2. IEC 243-3, 1993, Methods of test for electric strength of solid insulating materials - Part 3: Additional requirements for impulse tests.

3. Quisman, S., M. Steen-Andersen, J. Holboell and M. Henriksen "GFR-Materials Resistance to Lightning With Respect to Lightning Protection of Windmill Wings", International Conference on Lightning and Static Electricity 2003.

4. Larsen, F. M., Sorensen, T. "New Lightning Qualification Test Procedure for Large Wind Turbine Blades", International Conference on Lightning and Static Electricity 2003. 